九州大学学術情報リポジトリ

Kyushu University Institutional Repository

\title{
Study of Turbulence Intensity Effect on the Fatigue Lifetime of Wind Turbines
}

Ismaiel, Amr Mohamed Metwally

Interdisciplinary Graduate School of Engineering Sciences, Kyushu University | Faculty of Engineering and Technology, Future University in Egypt

Yosida, Shigeo

Research Institute for Applied Mechanics, Kyushu University

https://doi.org/10.5109/1929727

出版情報 : Evergreen. 5（1），pp.25-32，2018-03. 九州大学グリーンアジア国際リーダー教育センター バージョン：

権利関係 : 


\title{
Study of Turbulence Intensity Effect on the Fatigue Lifetime of Wind Turbines
}

\author{
Amr Mohamed Metwally Ismaiel ${ }^{1,2, *}$, Shigeo Yoshida ${ }^{3}$ \\ ${ }^{1}$ Interdisciplinary Graduate School of Engineering Sciences, Kyushu University, Japan. \\ ${ }^{2}$ Faculty of Engineering and Technology, Future University in Egypt (FUE), Egypt. \\ ${ }^{3}$ Research Institute for Applied Mechanics, Kyushu University, Japan. \\ *Author to whom correspondence should be addressed, \\ E-mail: amrmetwally@riam.kyushu-u.ac.jp
}

(Received November 14, 2017; accepted March 13, 2018).

\begin{abstract}
In this paper, the effect of variable turbulence intensities on the fatigue lifetime of wind turbines is studied. Time series aeroelastic simulations were carried on the NREL WindPACT 1.5MW upwind turbine using an open source software FAST. Two turbulence models -von Karman and Kaimal- were used with four different turbulence intensities (1\%, 10\%, 25\%, and 50\%). The time series data of the loads were post processed using the tool MLife to estimate the fatigue lifetime of the wind turbine. It is found that high turbulence intensities increase the extreme loadings on the turbine, increase damage equivalent loads, and decrease the estimated lifetime. It is also found that both turbulence models' results agree, there is no remarkable difference between them in the fatigue behavior of the turbine, and gave very close results.
\end{abstract}

Keywords: Aeroelasticity, Fatigue, Turbulence, Wind Turbine.

\section{Introduction}

The world intention towards renewable resources of energy has increased recently, because of the limitation of the amount of fossil fuels. In addition, most of the renewable resources provide clean energy with much less environmental problems ${ }^{1}$. Among the renewable energy sources, wind energy has a very high potential of development and growth year after year. Today's largest wind turbine is Vestas V164; its rated power is 9.5 MW and the world's cumulative installed wind capacity increased from 23,900 MW in the year 2001, to be 539,581 MW in the year 2017, with a growth rate of about $2000 \%$. This rate indicates the importance of wind energy ${ }^{2,3)}$. With the ongoing research in this field, the efficiency of converting wind energy into a usable form has increased significantly, and new techniques have evolved ${ }^{4-6)}$. Wind turbines are the conventional method of converting wind energy into mechanical energy, and then into other forms of energy, most probably electrical.

In order to benefit from the wind turbines ultimately, a certain level of functionality and operationality should be kept; It is a very important point to keep the wind turbine functional for the maximum lifetime possible. An estimation for the lifetime of the wind turbine can be calculated, and based on this estimation the design can be adjusted to fit the design requirements. Design lifetime for a wind turbine typically is twenty years of operation ${ }^{7)}$. One of the most important factors affecting the dynamics of the turbine, is the turbulence of the wind acting on it.
Turbulence of the wind means intense fluctuation of the loads acting on the turbine structure leading to fatigue.

Other parameters also affect the fatigue lifetime of wind turbines like icing, or operating scenarios. Many attempts were made to investigate the effect of different parameters on the wind turbine loading dynamics. The operating scenarios, which can be described also by the control actions, affect the dynamic loading of the wind turbine, by braking the rotor or giving pitch or yaw actions. These control actions' effect on the fatigue loading were studied by many researchers ${ }^{8-11)}$. Also, the effect of icing or climate change has been investigated ${ }^{12,13)}$. The computational methods for modeling the wind turbines, like Computational Fluid Dynamics (CFD) or Finite Elements Analysis (FEA), are very costly and time consuming ${ }^{14)}$. When many iterations are required, the aeroelastic tools developed by the National Renewable Energy Laboratory (NREL) become very useful, as they are based on advanced models, derived from the fundamental theory, but with suitable assumptions and simplifications, so they are very time efficient and suitable for huge number of iterations in a short period of time ${ }^{15,16)}$.

In this paper, the effect of different turbulence intensities on the fatigue behavior of the wind turbine is studied. The open source software tool TurbSim ${ }^{17)}$, developed by NREL, was used to simulate wind fields with different turbulence intensities using two different spectral models, over the NREL WindPACT 1.5MW upwind turbine ${ }^{18)}$. These wind fields were used for aeroelastic simulation of the wind turbine using the tool 
FAST $^{19)}$ to generate time series of the loads acting on the turbine. These time series were then post processed using MLife ${ }^{20)}$, a MATLAB ${ }^{\circledR}$ based code which uses Rainflow counting technique to estimate the fatigue life of the turbine.

The importance of this study is to anticipate the fatigue behavior of wind turbines according to turbulence in the wind, and know its effect on the lifetime.

Turbulence in the wind cannot be controlled as it is an environmental factor ${ }^{21}$, but it is important to know the effect of increasing the turbulence of the wind on the fatigue of turbine, so that it is considered in the design process of the turbine structure. A wind turbine used in a region where wind speeds are stable, can be designed less strictly, while regions of high turbulence intensity levels, or subject to phenomena like wind gusts or typhoons; the designer must take care of the effect of the severe turbulence on the structure dynamic loading.

By the end of this study, it is expected to see the effect of turbulence on the lifetime of the wind turbine. The turbulence is expected to affect the lifetime negatively, in a way that the larger the turbulence, the shorter the lifetime.

\section{Turbulence spectral models}

Behavior of the atmosphere varies in both spatial and time domains. Space variations generally depend on topographical conditions. Time variations can be categorized into four categories;

Inter-annual variations which occur in a time scale of more than one year,

Annual variations where seasonal wind speed variations occur all over the world,

Diurnal variations (Day time) where large wind speed variations occur on a day time scale specially in tropical and temperate latitudes, and

Short-term wind speed variations which occur in a time scale of less than ten minutes, including gusts and turbulence ${ }^{22)}$.

Turbulence can be defined as the random and fast fluctuation of wind speeds around its mean value, in a small time scale. These fluctuations occur in longitudinal, lateral, and vertical directions. The two main causes of turbulence are; friction with the ground caused by earth's topography, and thermal effects where air moves vertically as a result of temperature difference.

It is a complex process to represent the turbulence mathematically because it is a random process which cannot be simply described by deterministic equations. So, it is more useful to describe turbulence according to its statistical properties. Among the statistical properties which can describe the turbulence, is the turbulence intensity (TI $)^{23)}$. It measures the overall turbulence level, and can be defined as;

$$
I=\frac{\sigma}{\bar{U}}
$$

Where; I is the turbulence intensity, $\sigma$ is the standard deviation of the wind speed, and $\bar{U}$ is the mean wind speed. Both standard deviation and mean value of wind speeds are calculated over a time scale longer than that of the turbulence, but shorter than the time scale of other types of changes (e.g., Diurnal variations).

The turbulence spectrum is a description to the frequency of variation of the wind speed. The spectrum follows an asymptotic boundary which is, at high frequencies, proportional to $\mathrm{n}^{-5 / 3}$; where $\mathrm{n}$ is the frequency in $\mathrm{Hz}$, according to Kolmogorov law ${ }^{24)}$.

Two spectral models are commonly used to express the spectrum of the longitudinal wind component, denoted by a subscript "u”. Those models are the von Karman and Kaimal spectral models. They can be expressed as follows ${ }^{23)}$;

Kaimal:

$$
\frac{n S_{u}(n)}{\sigma_{u}^{2}}=\frac{4 n L_{1 u} / \bar{U}}{\left(1+6 n L_{1 u} / \bar{U}\right)^{5 / 3}}
$$

\section{von Karman:}

$$
\frac{n S_{u}(n)}{\sigma_{u}^{2}}=\frac{4 n L_{2 u} / \bar{U}}{\left(1+70.8\left(n L_{2 u} / \bar{U}\right)^{2}\right)^{5 / 6}}
$$

Where; $\mathrm{S}_{\mathrm{u}}(\mathrm{n})$ is the wind's longitudinal component's spectral density function, $\sigma_{\mathrm{u}}$ is the longitudinal wind speed's standard deviation, $L_{1 u}$ and $L_{2 u}$ are length scales with values depending on the surface roughness $\mathrm{z}_{0}$ and the above ground height $\mathrm{z}$.

The von Karman spectral model can give a better description for turbulence occurring in wind tunnel tests, while the Kaimal model fits better to the atmospheric turbulence ${ }^{25)}$. However, the von Karman model is consistent with the analytical formulae, and hence, often used for the correlation.

In this paper, both spectral models are used for the simulation, for the reason of comparison between their results. NREL engineers have developed many software tools to model and simulate the wind turbines. Among those software is the TurbSim, a tool which simulates turbulence fields around wind turbines. Different turbulence intensities have been used for the wind field generation. Although the value of turbulence intensity over a wind turbine can be calculated according to some standards, and depending on some parameters including surface roughness and height above ground ${ }^{26-28)}$, but in this study random turbulence intensities were used. The reason for this is that the purpose of the study is to know the effect of the turbulence intensities on the lifetime of a wind turbine. Accordingly, four different random values for turbulence intensities where chosen for the study, including very low turbulence (1\%), medium turbulence (10\%), high turbulence (25\%), and severe turbulence (50\%). Each turbulence intensity was modeled using both the von Karman and Kaimal models, then their results were used as an input to the software tool FAST; an aeroelastic tool for wind turbines. 


\section{Simulation results}

The wind turbine used for the simulation is the NREL WindPACT (Wind Partnership for Advanced Component Technologies) $1.5 \mathrm{MW}$ wind turbine. Originally, the WindPACT project aimed for studying the effect of scaling of different rotor configurations on the cost of energy (COE). Four different configurations are available for the WindPACT project; 0.75MW, 1.5MW, 3MW, and $5 \mathrm{MW}$. The baseline design properties of the $1.5 \mathrm{MW}$ configuration are shown in Table 1.

Table 1: Baseline Design Properties of WindPACT $1.5 \mathrm{MW}^{29)}$

\begin{tabular}{cc}
\hline \hline Rotor Diameter (m) & 70 \\
Hub Height (m) & 84 \\
Max Rotor Speed (rpm) & 20.5 \\
Hub Overhang (m) & 3.3 \\
Tower Base Diameter (m) & 5.663 \\
\hline \hline
\end{tabular}

The turbine specifications are used in the input file to TurbSim, to define the turbulence grid dimensions and position. Together with the meteorological boundary conditions, the input parameters to define the turbulent wind field are determined. The turbulence model and the turbulence intensity are chosen, then the simulation is run. The analysis time for the simulation was chosen to be 600 seconds, with a 0.05 s time step. The wind file is generated after running the input file using TurbSim, which is then used as one of the inputs to the FAST software tool.

Aeroelastic simulation is then performed on the wind turbine using FAST. Wind velocities and wind loads time series are generated. This simulation is performed for each turbulence model and for each turbulence intensity. In order to figure the change which turbulence intensities cause in the simulation, the wind speed is plotted with time for the first 40 seconds of the simulation. The extreme turbulence intensities of the von Karman spectral model, lowest and highest, are shown in figures 1 to 3 .

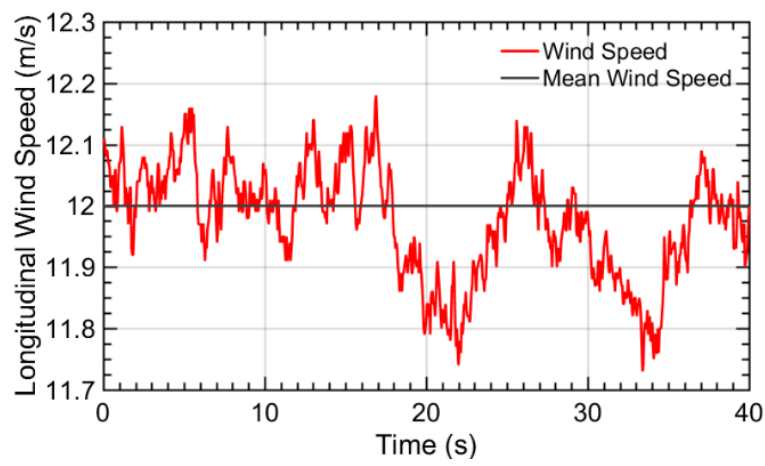

Fig. 1: Wind speed time series for von Karman model, $1 \%$ turbulence intensity

From Figure 1 we can notice that the wind speed is oscillating around the mean wind speed value of $12 \mathrm{~m} / \mathrm{s}$. But the oscillation is within a small range, from $11.7 \mathrm{~m} / \mathrm{s}$ to $12.18 \mathrm{~m} / \mathrm{s}$, since the turbulence intensity is very low with a value of $1 \%$.

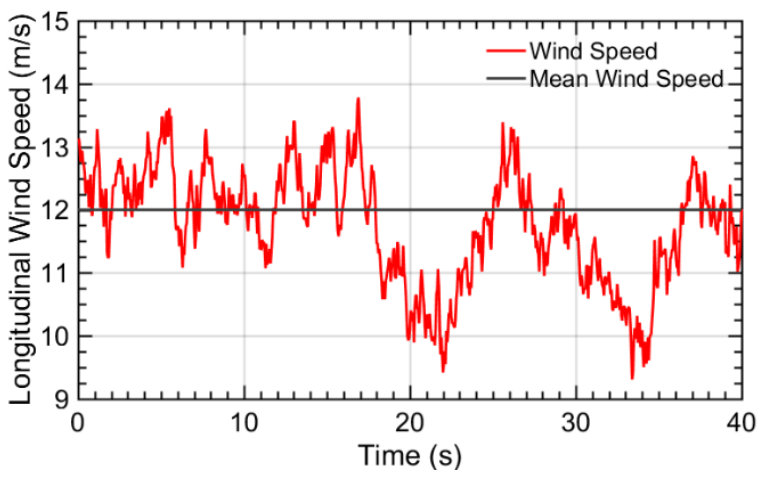

Fig. 2: Wind speed time series for von Karman model, $50 \%$ turbulence intensity

For a severe turbulence intensity of $50 \%$, the wind speed variation is very violent. The wind speed goes from as high as $13.8 \mathrm{~m} / \mathrm{s}$ to the lowest value of $8 \mathrm{~m} / \mathrm{s}$ in few seconds, and rises again, as observed from Figure 2.

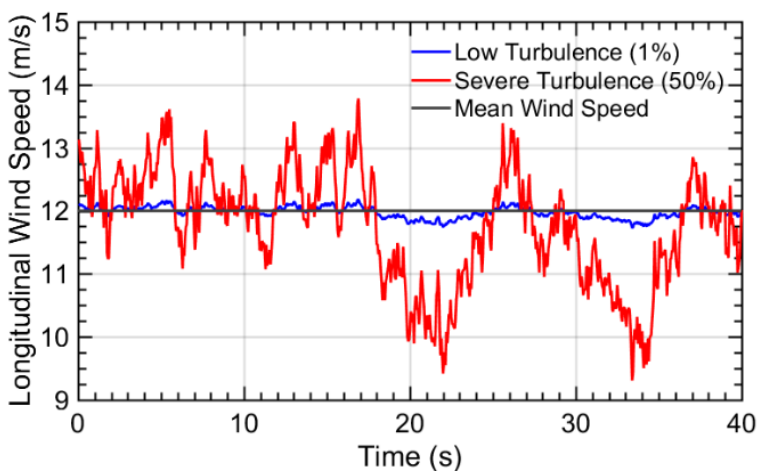

Fig. 3: Wind speed time series for von Karman model, lowest and highest turbulence intensities

When the two extreme turbulence intensities are shown together on the same scale in Figure 3, we can see the big difference between $1 \%$ and $50 \%$ turbulence intensities. The gap between minimum and maximum values of wind speed increases significantly in the high turbulent intensity, which induces severe wind dynamics.

The same simulations are also made for the Kaimal model, for the different intensity values.

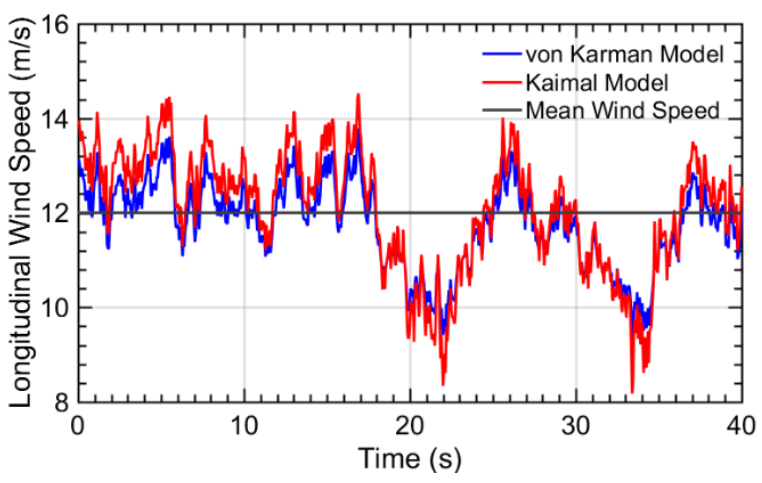

Fig. 4: von Karman vs. Kaimal model, turbulence intensity $50 \%$ 
The results of both models agree to a big extent. For comparison between the two models' wind fields, wind speed time series are plotted for both models for the turbulence intensity of $50 \%$ in Figure 4 . The behavior of both models is so much similar. However, the values are different, with the Kaimal model having slightly bigger gap between maximum and minimum values of the wind speeds. These values which will affect the results of each model. For the simulation part, only the von Karman simulation will be displayed for illustration, and the comparison between the two models will be shown with the results.

For both models, the turbulence intensities difference creates big variation in the wind field. This affects the dynamic loading of the wind turbine significantly. For instance, the axial force on the blade root is highly affected. This can be shown in Figure 5, for both the extreme values of the turbulence intensities.

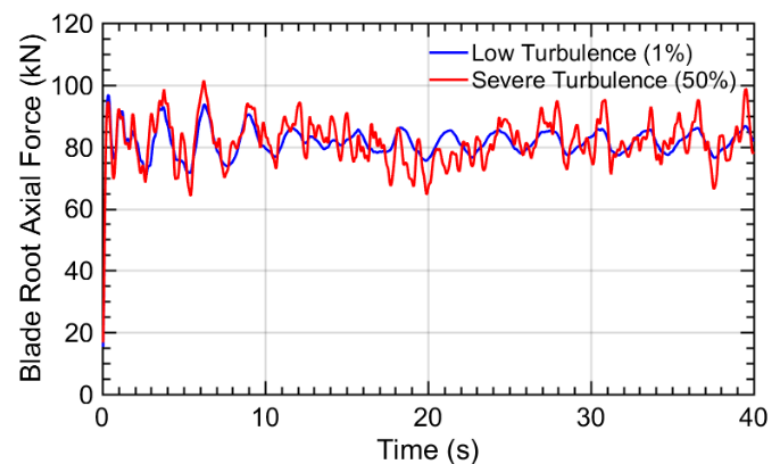

Fig. 5: Blade root axial force, von Karman model

The effect of turbulence intensity on the dynamic loading is obvious in Figure 5. For the low turbulence (1\%), the blade root force is oscillating around the mean value of $80 \mathrm{kN}$ smoothly, with a low frequency of change. While for the severe turbulence intensity, the oscillation of the force around the same mean value is violent. The frequency of changing the value of the force is very high in case of high turbulence. This frequent change in the value of the aerodynamic loads on the wind turbine negatively affect the turbine dynamics. The fatigue behavior is influenced by the dynamics in a way of decreasing the lifetime of the turbine.

\section{Results and discussion}

The simulation results made by FAST are then postprocessed using MLife. MLife is a MATLAB ${ }^{\circledR}$ based tool which can estimate the fatigue behavior of wind turbines. It uses Palmgren Miner's sum and Rainflow counting technique to calculate the fatigue cycles of one or combined time series. Damage equivalent loads and time until failure for aerodynamic loads' time series are calculated for each turbulence model and for the four different turbulence intensities.
The material properties of the WindPACT 1.5MW wind turbine are not completely defined in literature, some data are defined but some information is missing. The ultimate loads for the simulation were chosen based on the WindPACT maximum loading data ${ }^{18}$, while the blade and tower materials are not specified, so, the blade material is assumed to be made of composite material, using values of Wohler exponent $(\mathrm{m})^{30)}$ of 8 and 10 . And the tower is assumed to be steel, with a Wohler exponent of 3 .

Many simulations were run with different random seeds. The displayed results below are the averaged values of the results. The time series chosen for the simulation are the blade root axial and lateral forces $\left(\operatorname{Root}_{\mathrm{x}}\right.$ and $\operatorname{RootF}_{\mathrm{y}}$ ), blade root in-plane and out-of-plane bending moments $\left(\right.$ RootM $_{x}$ and RootM $\left.{ }_{y}\right)$ for the Wohler exponent value of 10 , and the tower base in-plane and out-of-plane bending moments (TwrBsM ${ }_{x}$ and $\mathrm{TwrBsM}_{\mathrm{y}}$ ).

In the following charts, the lifetime until failure for the chosen $\mathrm{S} / \mathrm{N}$ curves with different turbulence intensities using the von Karman spectral model will be displayed.

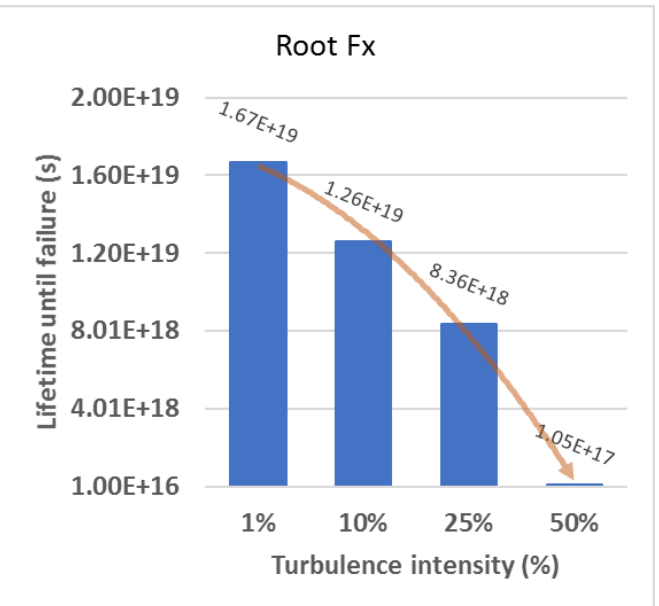

Fig. 6: Blade lifetime until failure for blade root axial force for different turbulence intensities (von Karman model)

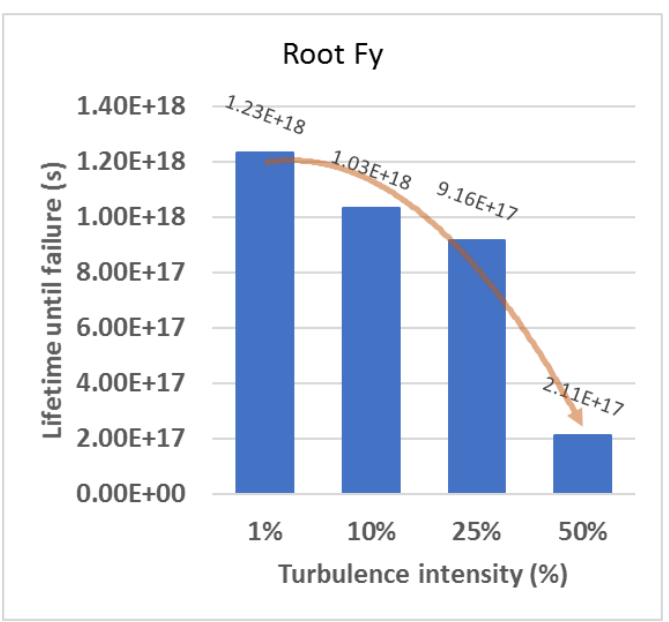

Fig. 7: Blade lifetime until failure for blade root lateral force for different turbulence intensities (von Karman model) 


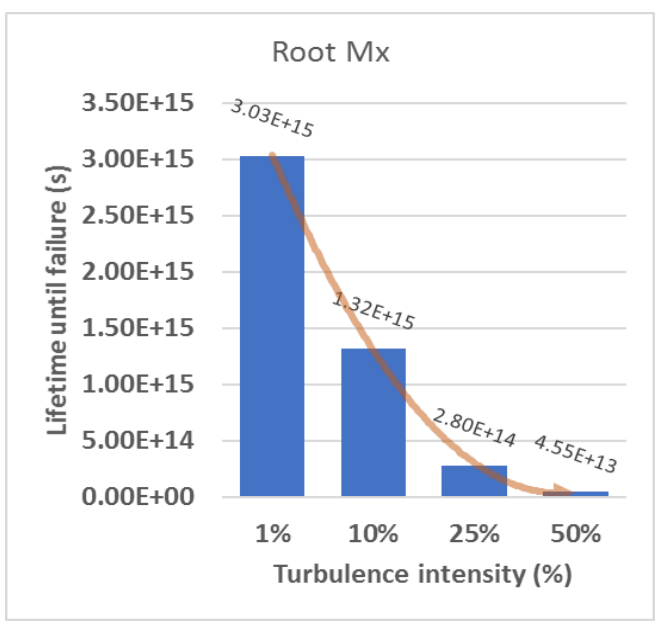

Fig. 8: Blade lifetime until failure for blade root in-plane bending moment for different turbulence intensities (von Karman model)

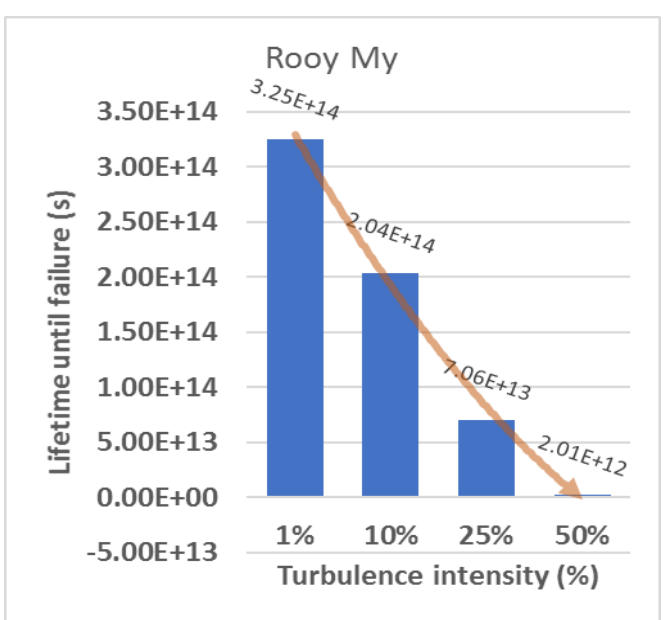

Fig. 9: Blade lifetime until failure for blade root out-ofplane bending moment for different turbulence intensities (von Karman model)

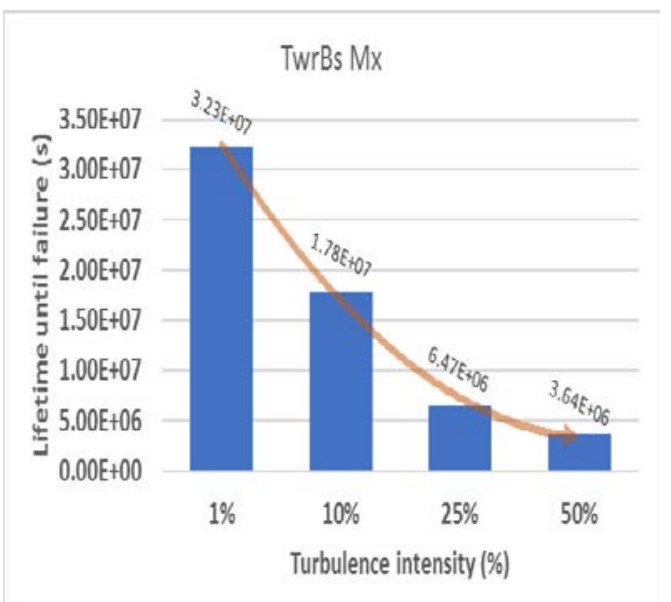

Fig. 10: Tower lifetime until failure for tower base inplane bending moment for different turbulence intensities (von Karman model)

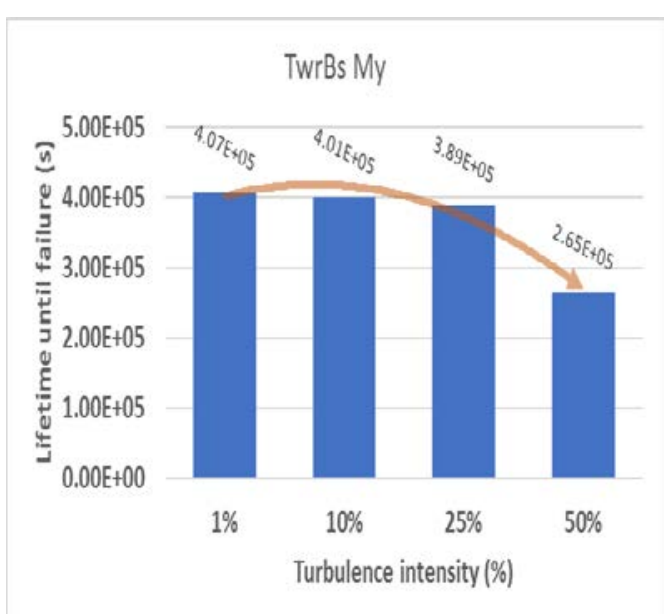

Fig. 11: Tower lifetime until failure for tower base outof-plane bending moment for different turbulence intensities (von Karman model)

In Figures 6-11, the life until failure in seconds, for various $\mathrm{S} / \mathrm{N}$ curves are shown. As it can be observed, there is no big difference in the values of the lifetime of the tower between the $1 \%$ and $10 \%$ turbulence intensities for most of the $\mathrm{S} / \mathrm{N}$ time series. The difference is in order of days or few months. For instance, in figures 10 and 11, the decrease in the lifetime of the tower because of the tower base in-plane bending moment $\left(\mathrm{M}_{\mathrm{x}}\right)$ is about 5 months (3.23E+7 seconds for $01 \%$ compared to $1.78 \mathrm{E}+7$ seconds for the $10 \%$ intensity), while the lifetime according to the out-of-plane bending moment $\left(\mathrm{M}_{\mathrm{y}}\right)$ increases for 5 hours for the higher intensity of $10 \%$. However, the difference for the lifetime of the blade is significant. The change of turbulence from $1 \%$ to $10 \%$ reduces the time until failure in order of years. The time until failure is extremely large, indicating lifetime in order of millions of years, because it is the lifetime for individual $\mathrm{S} / \mathrm{N}$ curves. Combined loads will result in different results regarding the lifetime. Also, the assumptions made for the values of the ultimate loads and the type of material must affect the results. However, using the same assumptions in all simulations, then it's only the effect of turbulence which makes the difference in the results. Slight change of turbulence from $1 \%$ to $10 \%$ made significant reduction in the time until failure. With increasing the value of the turbulence again to $25 \%$ and then to $50 \%$, the reduction increases. Comparing the two extremes of the turbulence intensities; $1 \%$ and $50 \%$, we can still see the difference in the lifetime of the tower is not highly affected. Reduction in lifetime because of the out-of-plane bending moment is one and half of a day, which is insignificant compared to the design lifetime of the turbine of 20 years. While for the blade, the reduction is in 0.01 order of magnitude.

Another descriptive parameter is the damage equivalent loads (DELs), or in other words, the relative fatigue. The fatigue damage due to the fluctuating loads over the life time is accumulated by MLife. In the following tables, the DELs are shown for the von Karman 
simulation for different time series. L_Ult is the ultimate load for each $\mathrm{S} / \mathrm{N}$ curve, and $\mathrm{m}$ is the Wohler exponent.

Table 2: Basic Lifetime DELs at fixed mean for various $\mathrm{S} / \mathrm{N}$ curves (von Karman model - 01\% TI)

\begin{tabular}{|c|c|c|c|c|c|c|c|}
\hline & & $\begin{array}{c}\text { RootFx } \\
\text { c1 } \\
(\mathbf{k N})\end{array}$ & $\begin{array}{c}\text { RootF } \\
\text { yc1 } \\
(k N)\end{array}$ & $\begin{array}{c}\text { Root } \\
\text { Mxc1 } \\
(\mathbf{k N} \cdot \mathbf{m})\end{array}$ & $\begin{array}{c}\text { Root } \\
\text { Myc1 } \\
(\mathbf{k N} \cdot \mathbf{m})\end{array}$ & $\begin{array}{c}\text { TwrBs } \\
\text { Mxt } \\
(\mathbf{k N} \cdot \mathbf{m})\end{array}$ & $\begin{array}{c}\text { TwrBs } \\
\text { Myt } \\
(\mathbf{k N} \cdot \mathbf{m})\end{array}$ \\
\hline L_Ult & & $5.6 \mathrm{E}+3$ & $5.6 \mathrm{E}+3$ & $2.76 \mathrm{E}+4$ & $2.76 \mathrm{E}+4$ & $3.2 \mathrm{E}+5$ & $3.2 \mathrm{E}+5$ \\
\hline L_MF & & 81.4 & 16.2 & 276 & 1580 & 1000 & $1.91 \mathrm{E}+4$ \\
\hline & 3 & & & & & 4040 & $1.66 \mathrm{E}+4$ \\
\hline \multirow[t]{2}{*}{ m } & 8 & 56.8 & 79.6 & 827 & 1100 & & \\
\hline & 10 & 62.2 & 81.6 & 848 & 1210 & & \\
\hline
\end{tabular}

Table 3: Basic Lifetime DELs at fixed mean for various $\mathrm{S} / \mathrm{N}$ curves (von Karman model - 10\% TI)

\begin{tabular}{|c|c|c|c|c|c|c|c|}
\hline & & $\begin{array}{c}\text { RootFx } \\
\text { c1 } \\
(\mathbf{k N})\end{array}$ & $\begin{array}{c}\text { RootF } \\
\text { yc1 } \\
(\mathrm{kN})\end{array}$ & $\begin{array}{c}\text { Root } \\
\text { Mxc1 } \\
(\mathbf{k N} \cdot \mathbf{m})\end{array}$ & $\begin{array}{c}\text { Root } \\
\text { Myc1 } \\
(\mathbf{k N} \cdot \mathbf{m})\end{array}$ & $\begin{array}{c}\text { TwrBs } \\
\text { Mxt } \\
(\mathbf{k N} \cdot \mathbf{m})\end{array}$ & $\begin{array}{c}\text { TwrBs } \\
\text { Myt } \\
(\mathbf{k N} \cdot \mathbf{m})\end{array}$ \\
\hline L_Ult & & $5.6 \mathrm{E}+3$ & $5.6 \mathrm{E}+3$ & $2.76 \mathrm{E}+4$ & $2.76 \mathrm{E}+4$ & $3.2 \mathrm{E}+5$ & $3.2 \mathrm{E}+5$ \\
\hline \multirow[t]{2}{*}{ L_MF } & & 81.7 & 16.3 & 279 & 1590 & 1010 & $1.91 \mathrm{E}+4$ \\
\hline & 3 & & & & & 4930 & $1.64 \mathrm{E}+4$ \\
\hline \multirow[t]{2}{*}{ m } & 8 & 56.9 & 81.5 & 917 & 1040 & & \\
\hline & 10 & 62.3 & 83.1 & 945 & 1140 & & \\
\hline
\end{tabular}

Table 4: Basic Lifetime DELs at fixed mean for various $\mathrm{S} / \mathrm{N}$ curves (von Karman model - 25\% TI)

\begin{tabular}{|c|c|c|c|c|c|c|c|}
\hline & & $\begin{array}{c}\text { RootFx } \\
\text { c1 } \\
(k N)\end{array}$ & $\begin{array}{c}\text { RootF } \\
\text { yc1 } \\
(k N)\end{array}$ & $\begin{array}{c}\text { Root } \\
\text { Mxc1 } \\
(\mathbf{k N} \cdot \mathbf{m})\end{array}$ & $\begin{array}{c}\text { Root } \\
\text { Myc1 } \\
(\mathbf{k N} \cdot \mathbf{m})\end{array}$ & $\begin{array}{c}\text { TwrBs } \\
\text { Mxt } \\
(\mathbf{k N} \cdot \mathbf{m})\end{array}$ & $\begin{array}{c}\text { TwrBs } \\
\text { Myt } \\
(\mathbf{k N} \cdot \mathbf{m})\end{array}$ \\
\hline L_Ult & & $5.6 \mathrm{E}+3$ & $5.6 \mathrm{E}+3$ & $2.76 \mathrm{E}+4$ & $2.76 \mathrm{E}+4$ & $3.2 \mathrm{E}+5$ & $3.2 \mathrm{E}+5$ \\
\hline L_MF & & 81.3 & 16.5 & 286 & 1590 & 1010 & $1.90 \mathrm{E}+04$ \\
\hline & 3 & & & & & 6900 & $1.64 \mathrm{E}+04$ \\
\hline \multirow[t]{2}{*}{$\mathbf{m}$} & 8 & 62 & 80.3 & 1110 & 1260 & & \\
\hline & 10 & 66.7 & 82.1 & 1160 & 1360 & & \\
\hline
\end{tabular}

Table 5: Basic Lifetime DELs at fixed mean for various $\mathrm{S} / \mathrm{N}$ curves (von Karman model - 50\% TI)

\begin{tabular}{|c|c|c|c|c|c|c|c|}
\hline & & $\begin{array}{c}\text { RootFx } \\
\text { c1 } \\
(\mathbf{k N})\end{array}$ & $\begin{array}{c}\text { RootF } \\
\text { yc1 } \\
(\mathrm{kN})\end{array}$ & $\begin{array}{c}\text { Root } \\
\text { Mxc1 } \\
(\mathbf{k N} \cdot \mathbf{m})\end{array}$ & $\begin{array}{c}\text { Root } \\
\text { Myc1 } \\
(\mathbf{k N} \cdot \mathbf{m})\end{array}$ & $\begin{array}{c}\text { TwrBs } \\
\text { Mxt } \\
(\mathbf{k N} \cdot \mathbf{m})\end{array}$ & $\begin{array}{c}\text { TwrBs } \\
\text { Myt } \\
(\mathbf{k N} \cdot \mathbf{m})\end{array}$ \\
\hline L_Ult & & $5.6 \mathrm{E}+3$ & $5.6 \mathrm{E}+3$ & $2.76 \mathrm{E}+4$ & $2.76 \mathrm{E}+4$ & $3.2 \mathrm{E}+5$ & $3.2 \mathrm{E}+5$ \\
\hline \multirow[t]{2}{*}{ L_MF } & & 79.1 & 16.4 & 294 & 1560 & 985 & $1.85 E+04$ \\
\hline & 3 & & & & & 7920 & $1.79 \mathrm{E}+04$ \\
\hline \multirow[t]{2}{*}{$\mathbf{m}$} & 8 & 105 & 97.3 & 1370 & 1930 & & \\
\hline & 10 & 112 & 105 & 1430 & 2030 & & \\
\hline
\end{tabular}

From Tables 2-5, we can observe that the DEL is following the same behavior as the time until failure. For the tower base, the DEL is increasing according to the inplane bending moment, while the out-of-plane bending moment is still not effective on the tower fatigue behavior. For the blades, the values of the DELs are almost doubled from $01 \%$ to the $50 \%$ turbulence intensity. This indicates the effect of the turbulence intensity on the fatigue behavior of the wind turbine.

The same procedure was made for the Kaimal spectral model. Very close results to that of the von Karman simulations appeared. The values of the lifetime until failure and the damage equivalent loads for both models are almost identical for the different wind turbulence intensities.

In order to compare between both models' results, the time until failure results are displayed in the following graph. It is impossible to plot all the time series on one graph with a regular scale, as there is a great difference between the values of the lifetime until failure from each time series to another. So, a log scale was used instead, but the real value of the lifetime until failure is displayed in the bar chart. Each time series' result is displayed for both spectral models. This graph is also useful to observe the difference between the values of the different time series, to know which is the more effective loading on the turbine.

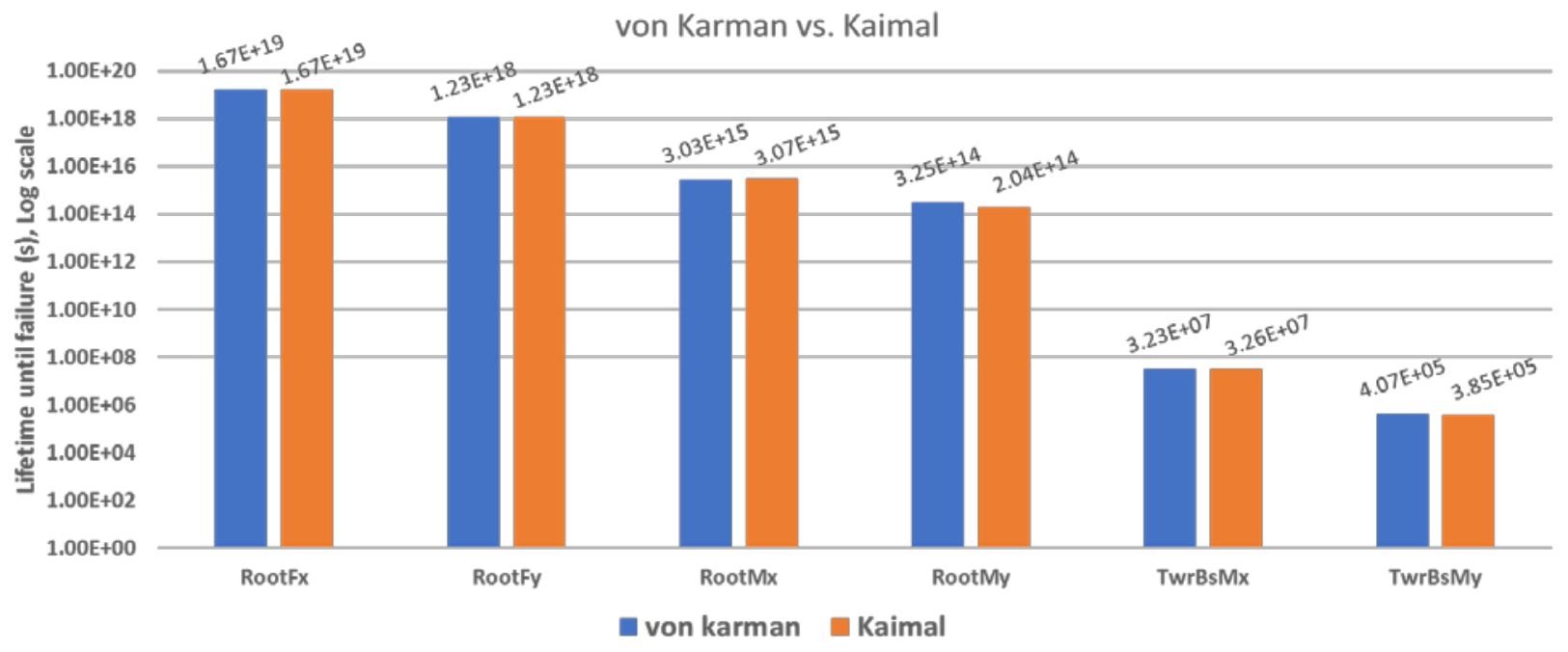

Fig. 12: Lifetime until failure, von Karman vs. Kaimal models' results 
From Figure 12, we can notice that both models gave almost identical results for most of the time series. Except for the out-of-plane bending moment for both the blade and the tower, the discrepancy between the values of lifetime until failure of both models is minimal. This indicates that both spectral models are effective in simulating the turbulent flow around the wind turbine.

Also, to compare the DELs, tables 6 and 7 show the results of the Kaimal model for the two high turbulence intensities of $25 \%$ and $50 \%$.

Table 6: Basic Lifetime DELs at fixed mean for various $\mathrm{S} / \mathrm{N}$ curves (Kaimal model - 25\% TI)

\begin{tabular}{|c|c|c|c|c|c|c|c|}
\hline & & $\begin{array}{c}\text { RootFx } \\
\text { c1 } \\
(\mathbf{k N})\end{array}$ & $\begin{array}{c}\text { RootF } \\
\text { yc1 } \\
(\mathrm{kN})\end{array}$ & $\begin{array}{c}\text { Root } \\
\text { Mxc1 } \\
(\mathbf{k N} \cdot \mathbf{m})\end{array}$ & $\begin{array}{c}\text { Root } \\
\text { Myc1 } \\
(\mathbf{k N} \cdot \mathbf{m})\end{array}$ & $\begin{array}{c}\text { TwrBs } \\
\text { Mxt } \\
(\mathbf{k N} \cdot \mathbf{m})\end{array}$ & $\begin{array}{c}\text { TwrBs } \\
\text { Myt } \\
(\mathbf{k N} \cdot \mathbf{m})\end{array}$ \\
\hline L_Ult & & $5.6 \mathrm{E}+3$ & $5.6 \mathrm{E}+3$ & $2.76 \mathrm{E}+4$ & $2.76 \mathrm{E}+4$ & $3.2 \mathrm{E}+5$ & $3.2 \mathrm{E}+5$ \\
\hline \multirow[t]{2}{*}{ L_MF } & & 85.7 & 18.2 & 318 & 1680 & 1140 & $2.02 \mathrm{E}+4$ \\
\hline & 3 & & & & & 6620 & $1.76 \mathrm{E}+4$ \\
\hline \multirow[t]{2}{*}{$\mathbf{m}$} & 8 & 56.9 & 80.3 & 1060 & 1240 & & \\
\hline & 10 & 62.3 & 82.1 & 1100 & 1350 & & \\
\hline
\end{tabular}

Table 7: Basic Lifetime DELs at fixed mean for various S/N curves (Kaimal model - 50\% TI)

\begin{tabular}{|c|c|c|c|c|c|c|c|}
\hline & & $\begin{array}{c}\text { RootFx } \\
\text { c1 } \\
(\mathbf{k N})\end{array}$ & $\begin{array}{c}\text { RootF } \\
\text { yc1 } \\
(\mathrm{kN})\end{array}$ & $\begin{array}{c}\text { Root } \\
\text { Mxc1 } \\
(\mathbf{k N} \cdot \mathbf{m})\end{array}$ & $\begin{array}{c}\text { Root } \\
\text { Myc1 } \\
(\mathbf{k N} \cdot \mathbf{m})\end{array}$ & $\begin{array}{c}\text { TwrBs } \\
\text { Mxt } \\
(\mathrm{kN} \cdot \mathbf{m})\end{array}$ & $\begin{array}{c}\text { TwrBs } \\
\text { Myt } \\
(\mathbf{k N} \cdot \mathbf{m})\end{array}$ \\
\hline L_Ult & & $5.6 \mathrm{E}+3$ & $5.6 \mathrm{E}+3$ & $2.76 \mathrm{E}+4$ & $2.76 \mathrm{E}+4$ & $3.2 \mathrm{E}+5$ & $3.2 \mathrm{E}+5$ \\
\hline \multirow[t]{2}{*}{ L_MF } & & 87.4 & 19.6 & 354 & 1720 & 1220 & $2.06 \mathrm{E}+4$ \\
\hline & 3 & & & & & 8240 & $2.07 \mathrm{E}+4$ \\
\hline \multirow[t]{2}{*}{$\mathbf{m}$} & 8 & 78.2 & 80.9 & 1320 & 1710 & & \\
\hline & 10 & 80.4 & 82.6 & 1370 & 1830 & & \\
\hline
\end{tabular}

From Tables 6 and 7, and comparing them to Tables 4 and 5 , the difference between the two models' DELs at $25 \%$ turbulence intensity is still trivial. While for the $50 \%$ turbulence intensity, there is an error with an order of magnitude of $10 \%$, which is still small error mentioning the randomness in generating the turbulent wind field.

\section{Conclusions}

From the discussed analyses, we can deduce that the turbulence intensity affects the fatigue behavior of the wind turbine significantly. The main trend of that effect is negative; the bigger the turbulence value, the shorter the lifetime until failure. This factor should be considered while designing the structure of a wind turbine, especially in areas subject to wind gusts or typhoons.

We can also conclude that some sections of the wind turbine are more affected by dynamics than others. The effect of turbulence was not so significant on the tower base, while on the blade root, the turbulence was very effective. The blade root is the most sensitive part of the wind turbine, since the blade vibrates during turbulence and the loads are concentrated at the fixed part of it; the root. Hence, the root part of the blade must be designed strong and flexible enough to stand for the severe dynamic loading in case of turbulence.

The two spectral models used for simulation gave very close results. Both models showed the same behavior with increasing the turbulence intensities. Trivial errors between the two models' results occurred. And this includes that any of the two models can be used for simulating wind field around a wind turbine.

\section{References}

1) Fthenakis, V., and Kim, H. C., Land use and electricity generation: A life-cycle analysis, Renewable and Sustainable Energy Reviews, 13, 6-7 (2009).

2) Wind Power Monthly website: https://www.windpowermonthly.com/10-biggestturbines

3) Global Wind Energy Council Website: http://gwec.net/wpcontent/uploads/2018/02/Global_Cumulative_Insta lled_Wind_Capacity_2001-2017.jpg

4) Yuanye Xia, Khaled H. Ahmed, and Barry W. Williams, A New Maximum Power Point Tracking Technique for Permanent Magnet Synchronous Generator Based Wind Energy Conversion System, IEEE Transactions on Power Electronics, V26-12, 3609-3620 (2011).

5) K. Tan, S. Islam, Optimum control strategies in energy conversion of PMSG wind turbine system without mechanical sensors, IEEE Transactions on Energy Conversion, V19-2, 392-399 (2004).

6) Wenxian Yang, Peter J. Tavner, Christopher J. Crabtree, and Michael Wilkinson, Cost-Effective Condition Monitoring for Wind Turbines, IEEE Transactions on Industrial Electronics, V57-1, 263271 (2010).

7) Wind Measurement International website: http://www.windmeasurementinternational.com/win d-turbines/om-turbines.php

8) Vasilis A.Riziotis and Spyros G.Voutsinas, Fatigue loads on wind turbines of different control strategies operating in complex terrain, Journal of Wind Engineering and Industrial Aerodynamics, V85-3, 211-240 (2000).

9) Dale E. Berg, David G. Wilson, Matthew F. Barone, Brian R. Resor, Jonathan C. Berg, Joshua A. Paquette and Jose R. Zayas, The Impact of Active Aerodynamic Load Control on Fatigue and Energy Capture at Low Wind Speed Sites, Sandia National Laboratory Article (2009).

10) S. Nourdine, H. Camblong, and I. Vechiu, Comparison of wind turbine LQG controllers using 
Individual Pitch Control to alleviate fatigue loads, Proceedings of the 18th Mediterranean Conference on Control \& Automation (MED), Morocco (2010).

11) Andreas Heege, Jaume Betran, and Yvan Radovcic, Fatigue load computation of wind turbine gearboxes by coupled finite element, multi-body system and aerodynamic analysis, Wind Energy, V10-5 (2010).

12) Peter Frohboese and Andreas Ander, Effects of Icing on Wind Turbine Fatigue Loads, Journal of Physics: Conference Series, 75, 012061 (2007).

13) S.C.Pryor, and R.J.Barthelmie, Climate change impacts on wind energy: A review, Renewable and Sustainable Energy Reviews, V14-1, 430-437 (2010).

14) Amr M. Halawa , Basman Elhadidi , and Shigeo Yoshida, POD \& MLSM Application on DU96W180 Wind Turbine Airfoil, Evergreen, V4-2, 36-43 (2017).

15) Jason Jonkman, The new modularization framework for the FAST wind turbine CAE tool, 51st AIAA Aerospace Sciences Meeting, Texas (2013).

16) Amr M M Ismaiel, Sayed M Metwalli, Basman Elhadidi, and Shigeo Yoshida, Fatigue Analysis of an Optimized HAWT Composite Blade, Evergreen, V4-2/3, 1-6 (2017).

17) B.J. Jonkman, and L. Kilcher, TurbSim User's Guide: Version 1.06.00, NREL/TP (2012).

18) D.J. Malcolm, and A.C. Hansen, WindPACT Turbine Rotor: Design Study, NREL/SR (2002).

19) Jason M. Jonkman, and Marshall L. Buhl Jr., FAST User's Guide, NREL/EL (2005).

20) G. J. Hayman, and M. Buhl, Jr., MLife User's Guide for version 1.00, NREL/TP (2012).

21) Arno J. Brand, Joachim Peinke, and Jakob Mann, Turbulence and wind turbines, Journal of Physics: Conference Series, 318 (2011).

22) James F. Manwell, Jon G. McGowan, and Anthony L. Rogers, Wind Energy Explained: Theory, Design and Application, 2nd Edition, John Wiley \& Sons, UK, (2009).

23) Tony Burton, Nick Jenkins, David Sharpe, and Ervin Bossanyi, Wind Energy Handbook, 2nd Edition, John Wiley \& Sons, UK, (2011).

24) Meneveau, C.; and Sreenivasan, K.R., The Multifractal Nature of Turbulent Energy Dissipation, Journal of Fluid Mechanics, 224 (1991).

25) Petersen, E.L., Mortensen, N.G., Landberg, L., Højstrup, J., and Frank, H.P., Wind power meteorology, Part I: Climate and turbulence, Wind Energy (1998).

26) DS 472, Code of practice for loads and safety of wind turbine constructions, DS 472, The Danish Society of Engineers and the Federation of Engineers (1992).

27) IEC, Wind turbine generator systems - Part 1: Safety requirements, International Standard 61400-1 edition 2, International Electrotechnical Commission, (1999).
28) IEC, Wind turbines - Part 1: Design requirements, International Standard 61400-1 (3rd edition), International Electrotechnical Commission, (2005).

29) Dayton A. Griffin, WindPACT Turbine Design Scaling Studies Technical Area 1 Composite Blades for 80- to 120-Meter Rotor, NREL (2001).

30) Shigley, J. E., Mischke, C. R., and Budynas, R. G., Mechanical Engineering Design, 7th Edition, McGraw Hill Higher Education, (2003). 